\title{
A General Method for $\alpha$-Functionalization of Enol Derivatives through the Umpolung Cross-Nucleophile Coupling Mediated by a Single lodine(III) Reagent
}

\author{
Víctor García-Vázquez, ${ }^{[a],{ }_{\perp}}$ Alba Carretero Cerdán, ${ }^{[a],[b]_{\perp}}$ Amparo Sanz-Marco, ${ }^{[a]_{\perp}}$ \\ Enrique Gómez-Bengoa ${ }^{[b]}$ and Belén Martín-Matute ${ }^{*[a]}$
}
[a] Víctor García Vázquez, Alba Carretero Cerdán, Dr. Amparo Sanz-Marco, Prof. Belén Martín-Matute. Department of Organic Chemistry, Stockholm University, Stockholm, SE-10691, Sweden; E-mail: belen.martin.matute@su.se
[b] Alba Carretero Cerdán, Prof. Enrique Gómez-Bengoa. Departamento de Química Orgánica I, University of the Basque Country, UPV/EHU 20080, Donostia-San Sebastián, Spain
$\perp \quad$ Equal contribution

Supporting information for this article is given via a link at the end of the document.

\begin{abstract}
In this paper, we present an unprecedented and general umpolung protocol that allows the functionalization of silyl enol ethers and of 1,3-dicarbonyl compounds with a large range of heteroatomic nucleophiles, including carboxylic acids, alcohols, primary and secondary amines, azide, thiols, and also anionic carbamates derived from $\mathrm{CO}_{2}$. The scope of the reaction also extends to carbon-based nucleophiles. The reaction relies on the use of 1-bromo-3,3-dimethyl-1,3dihydro- $1 \lambda^{3}[d][1,2]$ iodaoxole, which provides a key $\alpha$-brominated carbonyl intermediate. The reaction mechanism has been studied experimentaly and by DFT, and we propose formation of an unusual enolonium intermediate with a halogen-bonded bromide.
\end{abstract}

\section{Introduction}

The introduction of functional groups at the $\alpha$ carbon of carbonyl compounds is a common transformation in synthetic organic chemistry. $\alpha$-Functionalized ketones are substructures found in many natural products, pharmaceuticals, and other functional organic compounds. ${ }^{[1]}$ The functionalization reaction relies on the inherent nucleophilicity of the $\alpha$ carbon of the enol (or enolate) derivative of the carbonyl compound, which reacts with an electrophilic reaction partner in this process. Many carbon-based electrophiles can be used, leading to the formation of $\mathrm{C}-\mathrm{C}$ bonds, ${ }^{[2]}$ but the use of heteroatomic electrophiles becomes challenging. This is due to the high reactivity, and therefore limited functional-group compatibility of these species. They are typically strong oxidants, and this can lead to the formation of by-products, such as overfunctionalized or oxidized compounds. ${ }^{[3]}$ The structural variety of these species is also limited, and it is difficult to reconcile this with the idea of producing structurally diverse target compounds. Nevertheless, there are a number of heteroatomic electrophiles that can be used in such reactions, designed for specific transformations and with specific functional-group tolerances. ${ }^{[4]}$

An alternative approach is to use nucleophiles rather than electrophiles to react with enol derivatives. lodine(III) compounds have been used in this context to mediate the coupling of the two nucleophilic reactants through twoelectron oxidations, thereby inverting the polarity of one of the reagents. ${ }^{[5]}$ This strategy has recently been termed "cross-nucleophile coupling". ${ }^{[6]}$ This area has evolved significantly ${ }^{[7]}$ since the first report. ${ }^{[8]}$ When it comes to heteroatomic nucleophiles, the reaction usually requires a Lewis acid, as well as a low reaction temperature, in a one-pot two-step procedure, to avoid formation of by-products (Figure 1a). ${ }^{\left[{ }^{[9]}\right.}$ First the I(III) reagent and the enol derivative react at low temperature to form an enolonium intermediate. ${ }^{\left[{ }^{[a]}\right]}$ This ensures that the enol nucleophile is consumed before the second nucleophile is added at higher temperature (Figure 1a). In this way, side reactions such as homocoupling of the enol derivative or $\alpha$-functionalization with other nucleophiles derived from the I(III) reagent (e.g., OAc) are minimized. ${ }^{[9 a]}$ Using this protocol, Szpilman et. al elegantly observed O-enolonium species for the first time using ${ }^{13} \mathrm{C}$ NMR spectroscopy. ${ }^{[9 a]}$ The formation of by-products is closely related to the outstanding leaving ability of the I(III) functional group $\left(10^{6}\right.$ better than triflate $) .{ }^{[10]}$

In general, the nature of the second nucleophile is somewhat limited, but excellent results have been reported for arylations, ${ }^{[9 b, 9 c, 9 e, 11]}$ azidations, ${ }^{[7 c]}$ cyanations, ${ }^{[7 b]}$ and acetoxylations.${ }^{[7 d, 8,12]}$ The somewhat narrow scope is partly due to the fact that the nucleophile may need to be incorporated into the structure of the I(III) reagent. ${ }^{[7 b, 11,12,13]}$ General methods for the intermolecular reaction of ketones or enol derivatives with a variety of nucleophiles, using a non-designer I(III) reagent, are scarce. The Wirth group developed an effective approach to the formation of nitrogen- and oxygen- $\alpha$-substituted ketones through an internal umpolung strategy mediated by Phl(OAc)2 (Figure 1b). ${ }^{[7 a]}$ Their strategy relied on the use of a tethered nucleophile, i.e., the nucleophile was attached to the silicon center of the enol ether substrate (Figure 1b). Importantly, they were able to extend the scope of the reaction to the synthesis of chiral $\alpha$-substituted ketones when using chiral I(III) reagents. More recently, the Gulder group 
reported another elegant approach aimed at expanding the range of nucleophiles that can be used in such reactions. Here, 2-pyridyl ketones react by an umpolung coupling process mediated by a $\lambda^{3}$-fluoro iodane (Figure 1c). ${ }^{[14]}$ It was proposed that a noncovalent interaction between the $\mathrm{F}$ atom in the iodane and the pyridine moiety in the ketone substrate plays a key role in this reaction. Although this reaction is quite limited in terms of the ketone structure, a large number of nucleophiles could be coupled. Considering the ketone component, the majority of reported examples, with the exception of the pyridyl ketones used by Gulder, ${ }^{[14]}$ rely on the use of silyl enol ethers. ${ }^{[7 a-c, 7 e, 9 a, 9 b, 9 e]}$ Our own group contributed to this area of research with an umpolung protocol using allylic alcohols as enol synthons, in a reaction mediated by iridium catalysts (Figure 1d). This method gave $\alpha$-methoxy ketones from allylic alcohols, or $3(2 H)$-furanones from carbonyl-functionalized allylic alcohols. For all the examples, 1-fluoro-3,3-dimethyl-1,3-dihydro-1 $\lambda^{3}$-benzo[d][1,2]iodaoxole was used as an oxidant. ${ }^{[15]}$

$$
\text { (n) }
$$

Figure 1. Strategies for the umpolung $\alpha$-functionalization of ketones and enol derivatives. a) Cross-nucleophile coupling of silyl enol ethers with nitrogen nucleophiles. ${ }^{[7 \mathrm{Cc}]}$ b) Intramolecular cross-nucleophile coupling of nucleophile-functionalized silyl enol ethers. ${ }^{[7 a]}$ c) Crossnucleophile coupling of pyridyl ketones. ${ }^{[14]}$ d) Cross-coupling of allylic alcohols with nucleophiles. ${ }^{[15]}$ d) This work: general method for the cross-nucleophile coupling of silyl enol ethers with nucleophiles.

In this paper, we report the results of our investigations into the development of a method for the general reaction of unbiased silyl enol ethers (1) with a wide variety of heteronucleophiles, including carboxylic acids, thiols, alcohols, amines, azides, and even $\mathrm{CO}_{2}$ for the first time. Conveniently, in all instances, the same I(III) reagent is used. Thus the synthesis of substrate-specific iodanes is avoided, which contributes to the generality and applicability of the method. The mechanism of the reaction has been studied experimentally and by DFT calculations, and an unusual enolonium intermediate with a halogen-bonded bromide atom is proposed. From this 
enolonium, an $\alpha$-brominated carbonyl intermediate is formed, which is key for the high efficiency and the broad scope of the umpolung reaction.

\section{Results and Discussion}

Initially, we focused on the coupling of silyl ethers (1) and $\mathrm{CO}_{2}$ derivatives, by using carbamates formed in situ from amines (3) and $\mathrm{CO}_{2}$. This umpolung strategy would give access to $\alpha$-carbamoyl carbonyl compounds, which are important scaffolds in medicinal chemistry. ${ }^{[16]}$ Reported methods for the synthesis of $\alpha$-carbamoyl carbonyl compounds from $\mathrm{CO}_{2}$ are very scarce, and typically require the use of high pressures of $\mathrm{CO}_{2}$ and high temperatures. ${ }^{[17]}$ We started by generating carbamate anions by treating amine 3 with $\mathrm{NaH}$ under 1 atm of $\mathrm{CO}_{2}$, a modification of a procedure described by Trost for the synthesis of carbonates. ${ }^{[18]} \mathrm{A}$ variety of hypervalent iodine reagents (2a-f) were tested (Scheme 1) for the coupling of silyl enol ether 1a-TIPS with carbamate 4 . Surprisingly, only those benzoiodoxoles bearing a halide atom on the I(III) $(\mathbf{2 a}, \mathbf{2 c}$, and $\mathbf{2 d}$ ) yielded some amounts of $\alpha$ carbamoyl carbonyl product $\mathbf{5 a}$. Of these, it was 1-bromo-3,3-dimethyl-1,3-dihydro-1 $\lambda^{3}[d][1,2]$ iodaoxole $(\mathbf{2} \mathbf{c})$ that gave the best result $(27 \%$ yield of $\mathbf{5 a})$. Togni reagent $\mathbf{2} \mathbf{b}$, commonly used in radical additions of $\mathrm{CF}_{3}{ }^{\left[{ }^{[19]}\right.}$ left the starting silyl enol ether 1a-TIPS untouched. The use of Koser's reagent $2 \mathrm{e}$ led to the formation of by-products, and with phenyl- $\lambda 3$-iodanediyl diacetate (PIDA) (2f) again the starting enol ether 1a-TIPS was recovered.

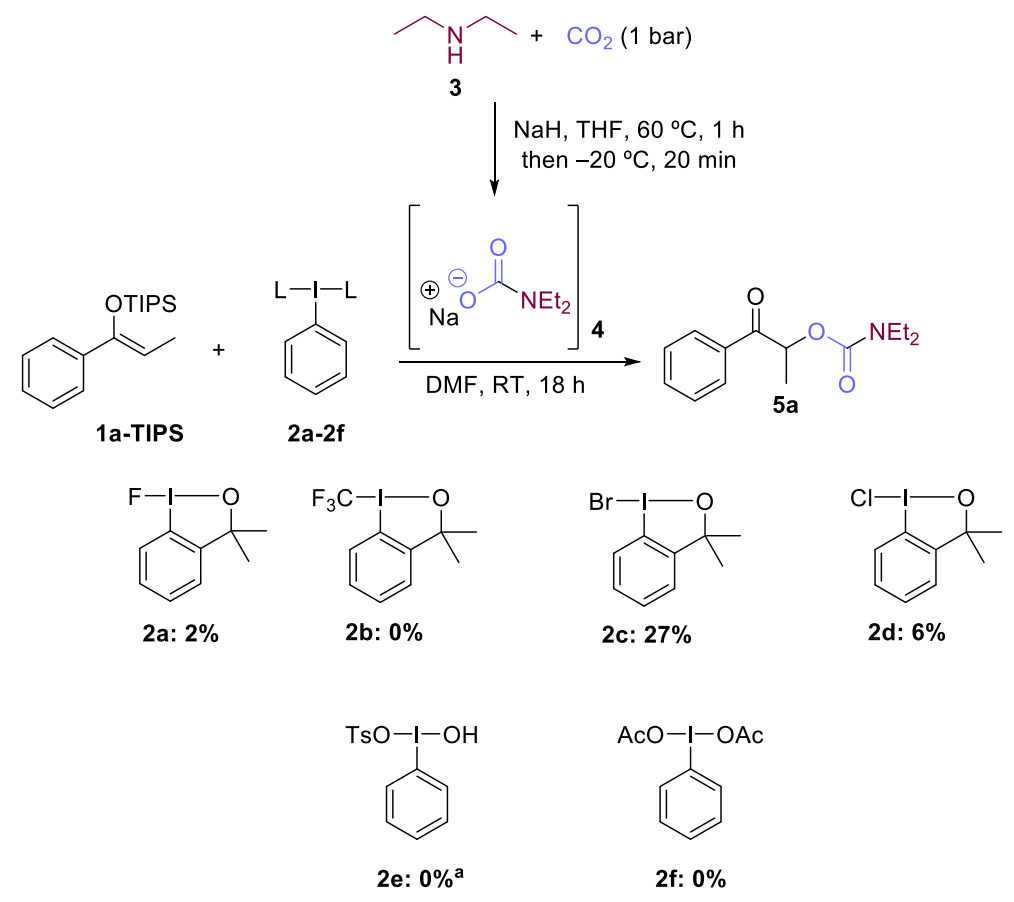

Scheme 1. Screening of hypervalent iodine(III) reagents. Reaction conditions: 1a-TIPS (0.1 mmol, 1 equiv.), 3 (0.2 mmol, 2 equiv.), iodine(III) reagent 2 ( $0.12 \mathrm{mmol}, 1.2$ equiv.), $\mathrm{NaH}$ ( $0.3 \mathrm{mmol}, 3$ equiv.), DMF ( $0.33 \mathrm{M}), \mathrm{RT}, \mathrm{CO}_{2}$ ( 1 bar), $18 \mathrm{~h}$. Yields determined by ${ }^{1} \mathrm{H}$ NMR spectroscopy using 2,3,5,6-tetrachlorobenzene as internal standard. ${ }^{a}$ Various products observed.

Further optimizations were carried out with reagent 2c (Table 1). When the number of equiv. of NaH was lowered to 1.5 , the yield increased substantially $(59 \%$, Table 1 , entry 3 vs entries $1-2)$. Lowering the amount of $\mathrm{NaH}$ further, or lowering the amount of amine 3 did not have a significant effect on the yield (Table 1, entries 4-5). On the other hand, with 1.5 equiv. of $\mathbf{2 c}$, a yield of $68 \%$ was obtained (Table 1, entry 6 ). Importantly, when the triisopropylsilyl group (TIPS, 1a-TIPS) was replaced by a tert-butyldimethylsilyl group (1a-TBS, Table 1, entry 7), product $\mathbf{5 a}$ was obtained in $77 \%$ yield. The less hindered trimethylsilyl group (1a-TMS, Table 1, entry 8 ) gave a lower yield. We also tested toluene, THF, 2-methyltetrahydrofuran, and acetone as reaction solvents, but the desired product was not observed (Table 1, entry 9 ). 
Table 1. Optimization studies ${ }^{[a]}$

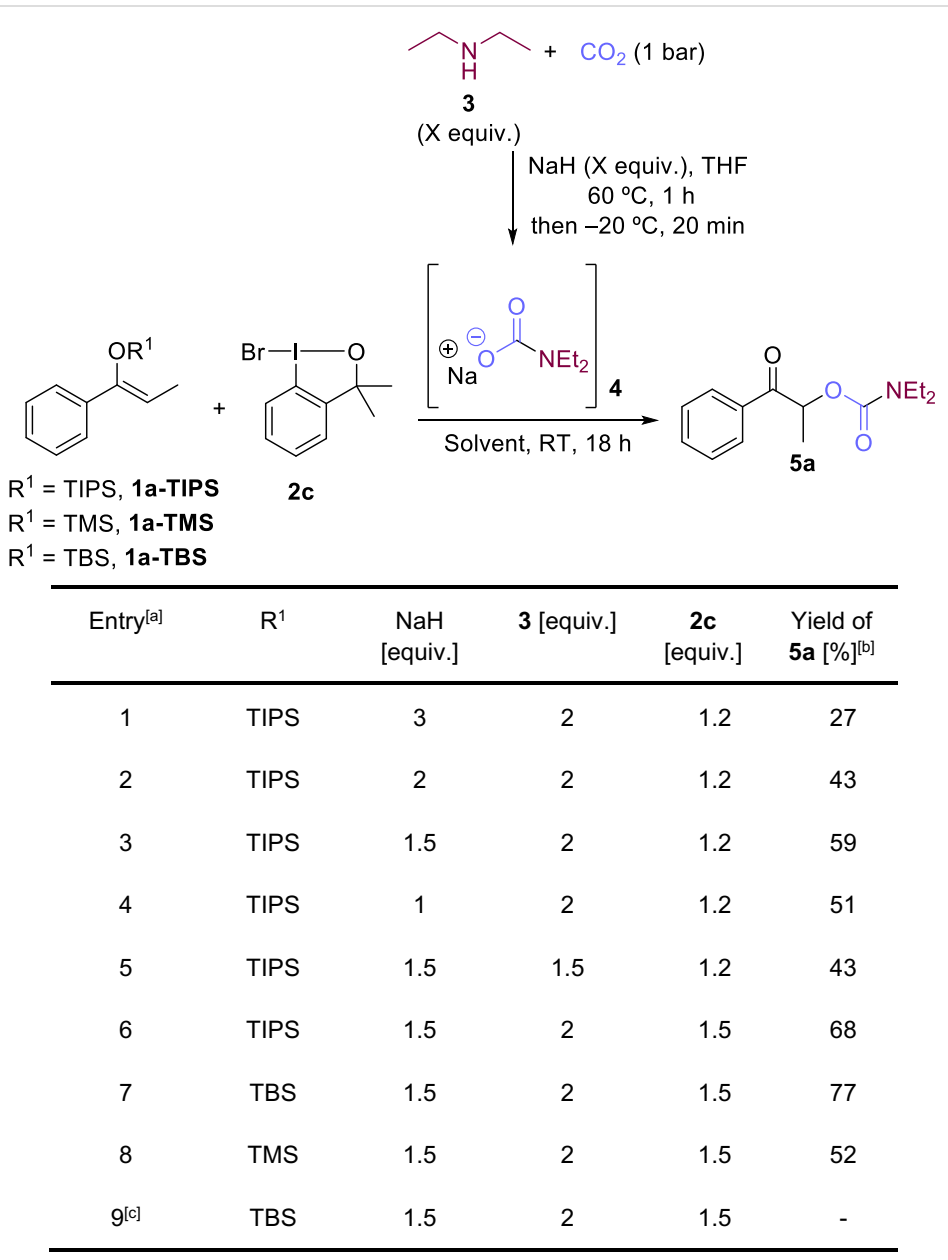

[a]: Reaction conditions: 1 ( $0.1 \mathrm{mmol}, 1$ equiv.) DMF (0.33 M), RT, $\mathrm{CO}_{2}$ ( 1 bar). [b]: Yields determined by ${ }^{1} \mathrm{H}$ NMR spectroscopy using $2,3,5,6$-tetrachlorobenzene $(0.1 \mathrm{mmol}, 1$ equiv.) as an internal standard. [c]: In toluene, THF, 2-methyltetrahydrofuran, or acetone (0.33 M).

We then applied the optimal conditions (Table 1, entry 7) to a number of TBS-enol ethers (Scheme 2a). With electron-donating groups at the para position of the aryl group at $\mathrm{R}^{1}$, the corresponding carbamates $\mathbf{5 b}$ and $\mathbf{5 c}$ were obtained with high efficiency ( 80 and $60 \%$ yields, respectively). Also, F-substituted silyl enol ether $2 \mathbf{d}$ gave $\mathbf{5 d}$ in $52 \%$ yield. Thiophene $1 \mathbf{e}$ gave the corresponding carbamate $\mathbf{5 e}$ in a good yield of $64 \%$. The reaction was found to be sensitive to steric effects on $R^{2}$. Thus, with an ethyl group at $R^{2}, \mathbf{5} \mathbf{f}$ was obtained in a lower yield (49\%). For aliphatic tert-butyldimethylsilyl enol ethers $1 \mathrm{~g}$ and $1 \mathrm{~h}$, yields of 51 and $46 \%$, respectively, were obtained. To assess the generality of the reaction, we tested different secondary amines to form the carbamate. Symmetrically and unsymmetrically substituted dialkyl amines reacted smoothly to give good yields (5i-5k, 60-80\%). Moreover, pyrrolidine substituted carbamate $\mathbf{5 I}$ was also obtained under the reaction conditions in $58 \%$ yield. However, carbamates derived from primary amines gave a mixture of unidentified products (not shown), which represents a major limitation of this approach. Significantly, this umpolung strategy is not limited to silyl enol ethers, but could be extended to the use of 1,3-dicarbonyl compounds. A $\beta$-ketoester 6 a reacted smoothly under the same conditions to give $7 \mathbf{a}$ in $82 \%$ yield. 1,3-Dicarbonyl compound $\mathbf{6 b}$ reacted with carbamate 4 to give $7 \mathbf{b}$ in good yield (56\%). The less nucleophilic $\beta$-amidoester $\mathbf{6 c}$ and malonate $\mathbf{6 d}$ gave carbamoyl derivatives $7 \mathbf{c}$ and $\mathbf{7 d}$ in good yields (68 and $78 \%$, respectively).

We went on to examine the generality of the cross-nucleophile coupling of silyl enol ethers with a variety of other nucleophiles (Schemes $2 b$ and $2 c$ ). Using both electron-poor and electron-rich benzoic acids as nucleophiles, $\alpha$ carboxylate-carbonyl compounds $\mathbf{8 a - 8 c}$ were obtained in excellent yields (80-98\%). When alcohols were tested as nucleophiles under otherwise identical reaction conditions, complex mixtures of unidentified by-products were formed. However, these difficulties were overcome by modifying the protocol; first silyl enol ether 1a was treated with I(III) reagent 2c. This was followed by the addition of the alcohol nucleophile (Method B). Using this procedure, $\alpha$-phenolate $8 \mathbf{d}$ was obtained in $66 \%$ yield. Thiols were also well tolerated, and thiophenol gave $8 \mathrm{e}$ in $60 \%$ yield 
using the standard procedure described above (i.e., Method A), and in $82 \%$ yield using Method B. An alkylsubstituted thiol gave a quantitative yield ( $8 \mathbf{f}$, Method B). Importantly, primary amines are also well tolerated, and benzylamine derivative $\mathbf{8} \mathbf{g}$ was obtained in $67 \%$ yield when using Method B. Cyclopropylamine reacted smoothly to give $8 \mathrm{~h}$ in $40 \%$ yield, which could be improved to $60 \%$ by using Method B. Piperidine gave $\alpha$-aminoketone $8 \mathrm{i}$ in $53 \%$ yield, and morpholine derivative $\mathbf{8 j}$ was obtained in $60 \%$ yield. Interestingly, carbon nucleophiles such as malonates also reacted smoothly, and $\mathbf{8 k}$ was formed in $50 \%$ yield. $\alpha$-Azido carbonyl compound $\mathbf{8} \mathbf{l}$ was obtained in $50 \%$ isolated yield.

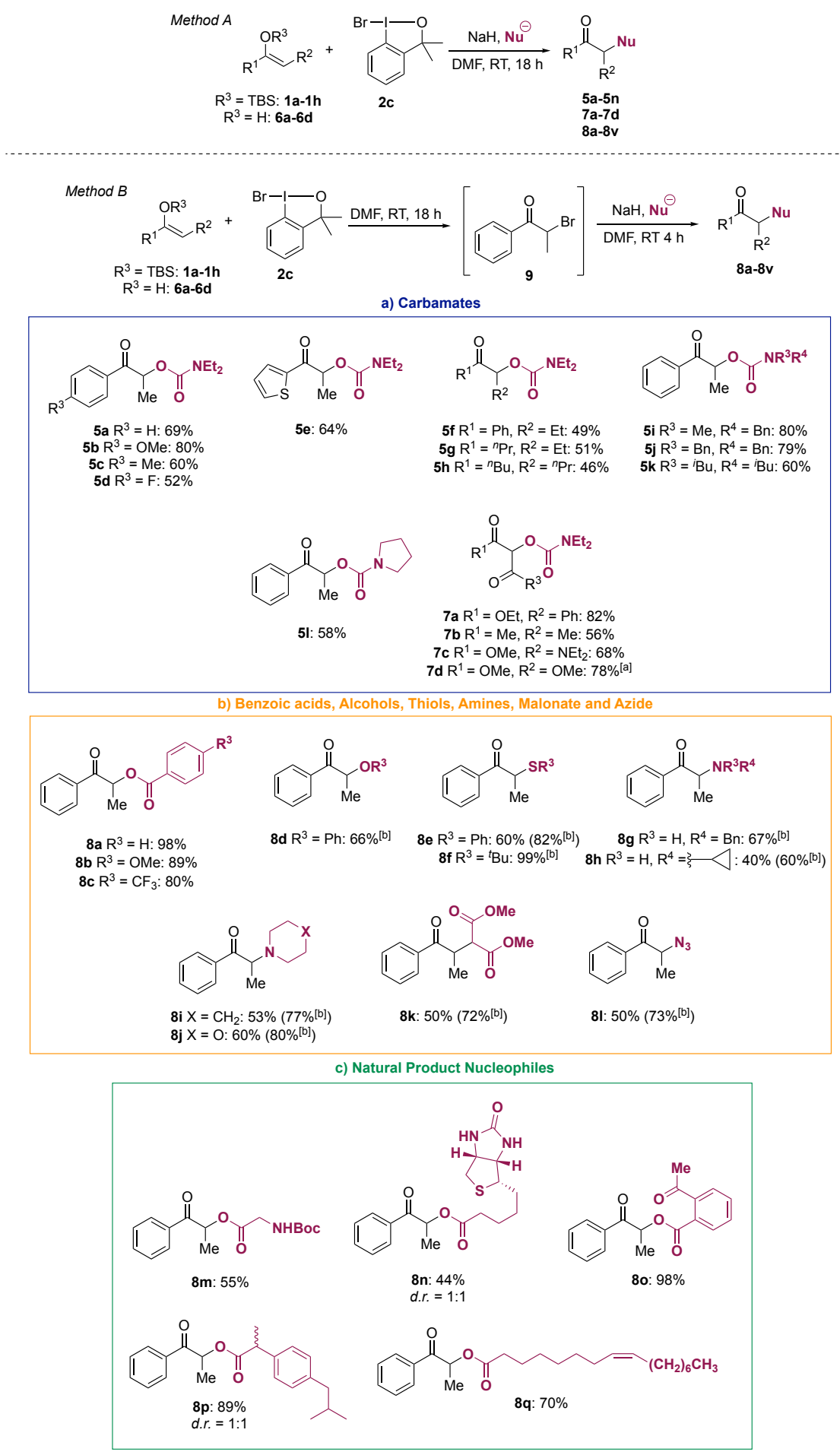

Scheme 2. Substrate scope for the umpolung cross-nucleophile-coupling reactions of silyl enol ethers with nucleophiles mediated by benzoiodoxole 2c. Unless otherwise mentioned, Method A was used: 1a-1h (0.1 mmol, 1 equiv.), 2c $(0.15 \mathrm{mmol}, 1.5 \mathrm{equiv}$.), NaH (0.15 mmol, 1.5 equiv.), nucleophile ( $\mathrm{Nu}^{2}, 0.2 \mathrm{mmol}, 2$ equiv.), DMF $(0.33 \mathrm{M}$ or $0.1 \mathrm{M}), \mathrm{RT}, 18 \mathrm{~h}(1 \mathrm{a}-1 \mathrm{~h}$ added as a solution in DMF to a tube containing the rest of the reactants). Isolated yields. [a]: Using 1-bromo-3,3-bis(trifluoromethyl)-1,3-dihydro-1 $\lambda^{3}$-benzo[d][1,2]iodaxole (2c') instead of 2c. [b]: Method B: two-step one-pot procedure, 1a $(0.1 \mathrm{mmol}, 1$ equiv. $), 2 c(0.15 \mathrm{mmol}, 1.5$ equiv. $)$, DMF (0.1 M), RT, $18 \mathrm{~h}$. After completion, $\mathrm{NaH}\left(0.15 \mathrm{mmol}, 1.5\right.$ equiv.) and nucleophile $\left(\mathrm{Nu}^{2}, 0.2 \mathrm{mmol}, 2\right.$ equiv.) were added. 
We went on to test a number of natural products and pharmaceuticals as nucleophiles in the reaction with 1aTBS. These compounds all contained carboxylic acid moieties in their structures (Scheme 2c). A BOC-protected glycine derivative gave $\mathbf{8 m}$ in $55 \%$ yield. With biotin as the nucleophile, compound $8 \mathrm{n}$ was obtained in $44 \%$ yield. Acetyl salicylic acid gave 80 in quantitative yield (98\% isolated yield), and ibuprofen gave $8 p$ in $87 \%$ yield. With the aliphatic oleic acid, $8 \mathbf{q}$ was formed in $70 \%$ yield.

Next, we focused our attention on studying the mechanism of the reaction. In an attempt to understand the dramatic effect of DMF as the reaction solvent, a variety of other polar aprotic solvents were tested. When the reaction of 1a, $\mathrm{CO}_{2}$, and diethylamine with $\mathbf{2 c}$ was run in MeCN, 2-bromo-1-phenylpropan-1-one (9) was detected as the sole product (Scheme 3a). $\alpha$-Bromo carbonyl compound $\mathbf{9}$ was also formed from $1 \mathrm{a}$ and $\mathbf{2 c}$ when the reaction was run in DMF in the absence of the nucleophile, in quantitative yield (Scheme $3 \mathrm{~b}$ ). We found that $\alpha$-bromo carbonyl derivative 9 reacted with the carbamate anion to give 5a in quantitative yield (see Supporting Information). Therefore, it is reasonable to suggest that the reaction might proceed by umpolung bromination followed by a nucleophilic substitution step with the second nucleophile, in this instance the carbamate generated from $\mathrm{CO}_{2}$. The formation of $\alpha$-substituted carbonyl derivatives as intermediates that can react with nucleophiles in $S_{N} 2$-type reactions has been previously studied by Maulide ${ }^{[20]}$ and Jorgensen ${ }^{[21]}$ among others, ${ }^{[22]}$ as a way to circumvent the inconvenience of using electrophilic reactants. Therefore, $2 \mathrm{c}$ seems to be an unusually mild brominating agent for the bromination of silyl enol ethers and 1,3-dicarbonyl compounds. Other brominating agents such as $\mathrm{NBS}_{\mathrm{O}} \mathrm{Br}_{2}$ lead to the formation of polybrominated products in their reactions with silyl enol ethers. ${ }^{[23]}$ We also tested NBS and $\mathrm{Br}_{2}$ (see Scheme S2) under the standard conditions described above, but the desired umpolung products, the $\alpha$-carbamoyl carbonyl compounds, were not detected in any case.

In the presence of radical scavengers, silyl enol ether $\mathbf{1 a}$ gave $\mathbf{5 a}$ in yields similar to those obtained in their absence (Scheme 3c and 3d vs Scheme 2), suggesting a non-radical pathway. We then tested the selectivity of the reaction towards the formation of $\alpha$-bromoketone 9 by adding $\mathrm{OH}^{-}$, as another potential nucleophile, to the reaction mixture (Scheme $3 \mathrm{e}$ ). It has been shown before that water is able to displace $\mathrm{I}(\mathrm{III})$ in the enolonium intermediates, and form $\alpha$-hydroxy ketones (i.e. 10). However, when adding a large excess of $\mathrm{OH}^{-}$, under otherwise identical reactions conditions, only $\alpha$-bromoketone 9 was formed in $99 \%$ yield.

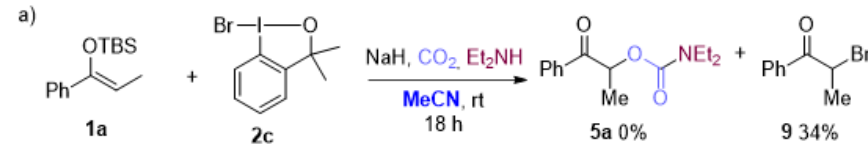

b)

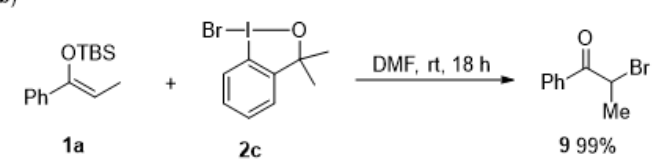

c)

$99 \%$

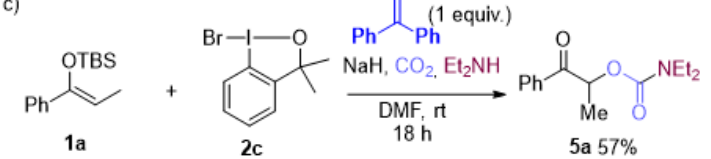

d)
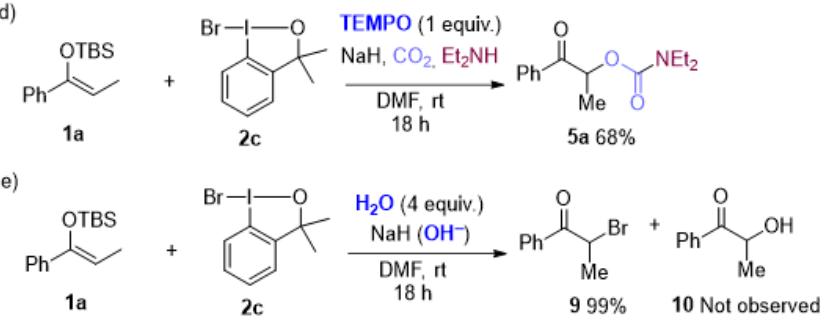

Scheme 3. Control experiments and mechanistic investigations. 
To further understand the mechanism of the cross-nucleophile-coupling reaction mediated by bromobenzoidoxole 2c, we turned to DFT calculations at the $B 3 L_{Y P}{ }^{[24]}$ and $M 06^{[25]}$ functional levels using the Gaussian 16 software ${ }^{[26]}$ (see Supporting Information for more details). The calculations were carried out using the sum of the energies of enolate species ${ }^{[11]} I$ and iodine(III) reagent $2 \mathrm{c}$ as the reference point ( $\mathrm{G}=0 \mathrm{kcal} / \mathrm{mol}$ ) of the energy profile (Figure 2 , middle). The enolate can attack the iodine atom either through the oxygen or through the carbon of the enolate, leading to formation of at least three possible low-energy enolonium intermediates (O-enolonium-II $(-2.0$ $\mathrm{kcal} / \mathrm{mol}), \mathbf{C}$-enolonium-II $(-3.0 \mathrm{kcal} / \mathrm{mol})$, and C-enolonium-II' $(0.2 \mathrm{kcal} / \mathrm{mol})$. In all cases, the formation of the enolate-iodine bond occurs in the position trans to the phenyl-I substituent, inducing an elongation of the $\mathrm{Br}-\mathrm{I}$ bond. In the starting compound $\mathbf{2 c}$, the $\mathrm{Br}-\mathrm{I}$ bond is short, i.e., $2.9 \AA$. This bond length is increased in O-enoloniumII (3.17 $\AA)$, and even more so in C-enolonium-II $(3.20 \AA)$ and C-enolonium-II (3.29 $\AA)$. These distances are similar to those found in structures with a halogen bond between iodine and bromine atoms. ${ }^{[27]}$ The three calculated intermediates are almost isoenergetic and they could, therefore, be in equilibrium. The direct reductive ligand coupling of the bromine and enolate fragments of these enolonium intermediates was calculated to be feasible. For example, $\mathbf{T S}_{\boldsymbol{I I I I}}$ and $\mathbf{T S}_{\boldsymbol{I I}-\mathrm{IV}}$ have calculated activation energies of $18-19 \mathrm{kcal} / \mathrm{mol}$ from their respective enolonium intermediates, O-enolonium-II $(-2.0 \mathrm{kcal} / \mathrm{mol})$ and C-enolonium-II' $(0.2 \mathrm{kcal} / \mathrm{mol})$. Interestingly, a transition state was found for the isomerization of the enolate substituent, which rotates from the trans to the cis position relative to the phenyl-I bond, displacing the bromine atom from the coordination sphere of the iodine. This transition state $\left(\mathbf{T S}_{\mathrm{II}-\mathrm{III}}, \Delta \Delta \mathrm{G}^{\ddagger}=16.2 \mathrm{kcal} / \mathrm{mol}\right.$ ) is low in energy, and leads to enolonium intermediate $\mathrm{C}$-enoloniumIII. From here, backside attack by the bromide (TS III-IV) on the $\alpha$-carbon in C-enolonium-III has the lowest calculated energy for $\mathrm{C}-\mathrm{Br}$ formation $\left(\Delta \Delta \mathrm{G}^{\ddagger}=15.8 \mathrm{kcal} / \mathrm{mol}\right)$. In contrast, the syn attack represented by $\mathrm{TS}_{\text {III-IV }}$ is too high energy to take place under these reaction conditions $\left(\Delta \Delta \mathrm{G}^{\ddagger}=35.7 \mathrm{kcal} / \mathrm{mol}\right)$. Thus, our DFT calculations show that the formation of the $\alpha$-bromo ketone intermediate INT-IV is feasible under the reaction conditions starting from the enolate and iodine(III) reagent 2c. This pathway is possible in the absence of any external nucleophilic anion. After that, intermediate $\alpha$-bromoketone $\mathbf{9}$ evolves via a nucleophilic displacement upon reaction with the heteronucleophiles (Scheme S2).

Both DFT calculations and experimental studies support the formation of $\alpha$-bromoketone 9 as an important intermediate in this cross-nucleophile coupling. This umpolung event is mediated by benzoidoxole $\mathbf{2 c}$, and can occur by three possible mechanisms. Pathway A and pathway B are analogous mechanisms involving Oenolonium-II and C-enolonium-II', respectively, in which bromide interacts with the I(III) through a halogen bond (3.17 and 3.20 $\AA$, respectively). ${ }^{[27 b]}$ These species then undergo a reductive coupling step to give $\alpha$-bromoketone 9. These $\mathrm{Br}-\mathrm{l}$ interactions might explain the lack of by-products. As mentioned above, the formation of by-products such as dimers $\left(\mathrm{Nu}^{2}=1\right)$ or $\alpha$-hydroxy ketones $\left(\mathrm{Nu}^{2}=\mathrm{OH}^{-}\right.$, Scheme 3e) has been a major limitation in similar I(III)mediated umpolung approaches. We have also observed by-product formation when using other I(III) reagents, e.g., with $\mathbf{2 a}$ in our previous work, ${ }^{[15]}$ and with $\mathbf{2 e}$ in the optimization experiments described in this paper (Scheme 1). Alternatively, pathway $C$ can occur via $\mathbf{C}$-enolonium-III, which is formed by ligand rearrangement around the I(III) center of $\mathbf{C}$-enolonium-II. In pathway $\mathrm{C}$, the bromide atom is not interacting with the I(III) center ( $\mathrm{Br}-\mathrm{I}$ distance is $5.16 \AA$ ) of $\mathbf{C}$-enolonium-III. From here, a nucleophilic attack of the $\mathrm{Br}^{-}$on the very electrophilic ${ }^{[10]} \alpha-\mathrm{C}$ of $\mathbf{C}$ enolonium-III also leads to $\alpha$-bromoketone $9\left(16.2 \mathrm{kcal} / \mathrm{mol}\right.$ for isomerization and $15.8 \mathrm{kcal} / \mathrm{mol}$ for the $\left.\mathrm{S}_{\mathrm{N}} 2 \mathrm{step}\right)$. The DFT calculations do not show a strong preference for any of the three pathways explored. However, if Cenolonium-III is involved (pathway C), we would expect the highly electrophilic enolonium ${ }^{[10]}$ (C-enolonium-III) to react also with any of the nucleophiles present in the reaction mixture, such as starting enol 1 or $\mathrm{HO}^{-}$(Scheme $3 \mathrm{e}$ ) to form by-products. The control experiment in Scheme $3 \mathrm{~b}$ also shows that $\alpha$-bromoketone 9 is the sole product formed in the absence of the heteronucleophile $\left(\mathrm{Nu}^{2}\right)$. The absence of by-products may be explained through a reaction pathway in which an intramolecular reaction results in formation of the $\mathrm{C}-\mathrm{Br}$ bond formation (pathways $\mathrm{A}$ and $\mathrm{B}$ ), rather than through an intermolecular nucleophilic displacement of $\mathrm{I}(\mathrm{III})$ on the enolonium intermediates (pathway C). 


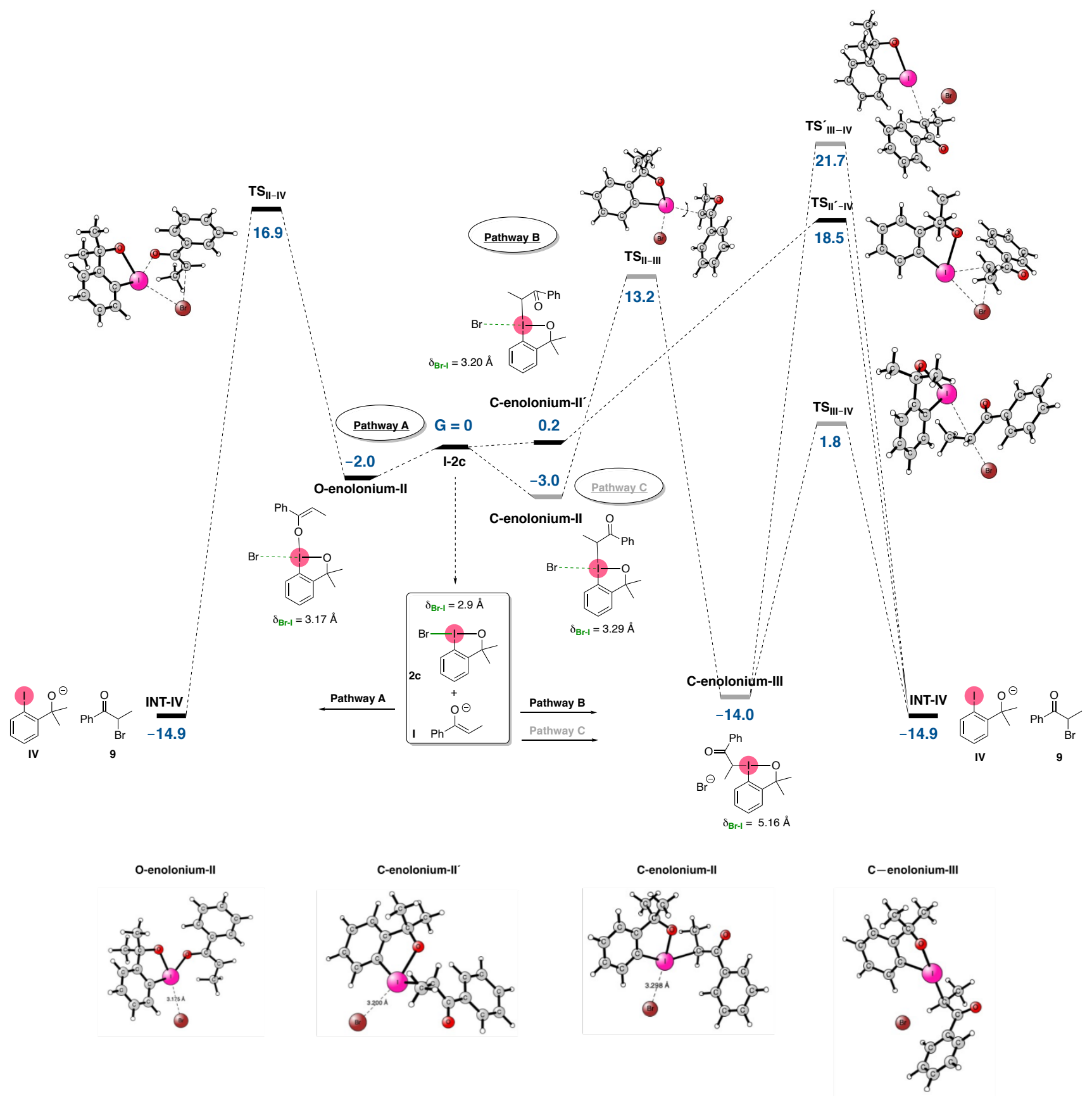

Figure 2. Top: Reaction mechanisms for the umpolung cross-nucleophile coupling of enol derivatives mediated by hypervalent iodine(III) reagent 2c. Values are given in $\mathrm{kcal} / \mathrm{mol}$. Bottom: 3-D Structures of enolonium intermediates.

\section{Conclusion}

We have developed an umpolung method for the cross-nucleophile coupling of enol derivatives with a variety of nucleophiles, using a single iodine(III) reagent. The reactions occur with good efficiency, and by-products are not formed. Using the method described here, $\mathrm{CO}_{2}$ has been used, in the form of anionic carbamates, in their reaction with silyl enol ethers for the first time. Additionally, benzoic acids, alcohols, thiols, primary and secondary amines, malonate and an azide have been used as nucleophiles in the transformation. We have also used this approach to derivatize natural products and drugs. Mechanistic evidence and DFT calculations have shown that $\alpha-$ bromoketones are formed as reaction intermediates. DFT calculations indicate that the mechanism may proceed via enolonium species containing $\mathrm{I}-\mathrm{Br}$ halogen bonds. This may be key for the generality and high selectivity of the reaction. 


\section{Experimental Section}

General procedures for the cross-nucleophile-coupling reaction:

Method A: A solution of the nucleophile $(0.2 \mathrm{mmol}, 2$ equiv. $)$ in DMF ( $0.33 \mathrm{~mL}$ or $1 \mathrm{~mL}, 0.33 \mathrm{M}$ or $0.1 \mathrm{M}$ of 1$)$ was added to a vial containing 1 ( $0.1 \mathrm{mmol}, 1$ equiv.), $\mathrm{NaH}(0.15 \mathrm{mmol}, 1.5$ equiv.), and $2 \mathrm{c}(0.15 \mathrm{mmol}, 1.5$ equiv.). The reaction mixture was stirred at room temperature for $18 \mathrm{~h}$. After this time, the mixture was extracted with EtOAc $(3 \times 5 \mathrm{~mL})$. The organic phases were combined and washed with water three times. The organic phase was then dried $\left(\mathrm{MgSO}_{4}\right)$, and the solvent was evaporated under reduced pressure. The residue was purified by flash column chromatography using silica gel as the stationary phase, eluting with a pentane/EtOAc mixture (5 to $100 \%$ EtOAc), to give the desired products.

Method B: DMF (0.5 mL, $0.2 \mathrm{M})$ was added to a vial containing 1 ( $0.1 \mathrm{mmol}, 1$ equiv.) and $2 \mathrm{c}(0.15 \mathrm{mmol}, 1.5$ equiv.). The reaction mixture was stirred at room temperature for $18 \mathrm{~h}$. After this time, the formation of $\mathbf{9}$ was complete. A solution of the nucleophile ( $0.2 \mathrm{mmol}, 2$ equiv.) and $\mathrm{NaH}(0.15 \mathrm{mmol}, 1.5$ equiv. $)$ in DMF $(0.5 \mathrm{~mL}$, to reach $0.1 \mathrm{M}$ of 1$)$ was added to the mixture. The reaction mixture was stirred at room temperature for a further $4 \mathrm{~h}$. After this time, the mixture was extracted with EtOAc $(3 \times 5 \mathrm{~mL})$, and the organic phases were combined and washed with water several times. The organic phase was then dried $\left(\mathrm{MgSO}_{4}\right)$, and the solvent was evaporated under reduced pressure. The residue was purified by flash column chromatography using silica gel as the stationary phase, eluting with a pentane/EtOAc mixture (5 to $100 \%$ EtOAc), to give the desired products.

All other experimental data and characterization is provided in the Supporting Information.

\section{Acknowledgements}

The authors are grateful for support from the Swedish Research Council through Vetenskapsrådet, and from the Göran Gustafsson Foundation. This project was also funded by the European Union's Horizon 2020 research and innovation programme under Grant Agreement 721223.

Keywords: Hypervalent iodine(III) • Umpolung • Enol derivatives $・$ DFT • Mechanistic insight

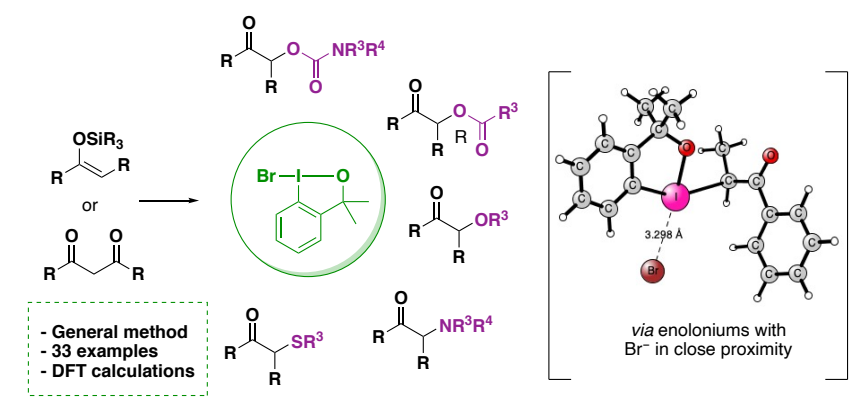

\section{References}

[1] a) J. Magano, J. R. Dunetz, Org. Process Res. Dev. 2012, 16, 1156-1184; b) S. Rossi, A. Puglisi, L. Raimondi, M. Benaglia, Chem CatChem 2018, 10, 2717-2733; c) P. K. Prasad, R. N. Reddi, S. Arumugam, Org. Biomol. Chem. 2018, 16, 9334-9348; d) L. A. T. Allen, R.-C. Raclea, P. Natho, P. J. Parsons, Org. Biomol. Chem. 2021, 19, 498-513.

[2] a) R. Cano, A. Zakarian, G. P. McGlacken, Angew. Chem. Int. Ed. 2017, 56, 9278-9290; b) Y. Liu, S.-J. Han, W.-B. Liu, B. M. Stoltz, Acc. Chem. Res. 2015, 48, 740-751.

[3] a) E. Differding, G. M. Rüegg, R. W. Lang, Tetrahedron Lett. 1991, 32, 1779-1782; b) J. A. Nobrega, S. M. C. Gonçalves, C. Peppe, Synth. Commun. 2002, 32, 3711-3717; c) B. Sreedhar, P. Surendra Reddy, M. Madhavi, Synth. Commun. 2007, 37, 4149-4156; d) T. Kösel, G. Dräger, A. Kirschning, Org. Biomol. Chem. 2021, 19, 2907-2911.

[4] a) a) S. Stavber, M. Jereb, M. Zupan, Synthesis 2002, 2002, 2609-2615; b) T. Baumann, H. Vogt, S. Bräse, Eur. J. Org. Chem. 2007, 2007, 266-282; c) H. Jia, A. P. Häring, F. Berger, L. Zhang, T. Ritter, J. Am. Chem. Soc. 2021, 143, 7623-7628. d) J. M. Janey, Angew. Chem. Int. Ed. 2005, 44, 4292-4300; e) A. M. R. Smith, K. K. Hii, Chem. Rev. 2011, 111, 1637-1656.

[5] V. V. Zhdankin, P. J. Stang, Chem. Rev. 2008, 108, 5299-5358.

$\left[{ }^{6}\right] \quad$ A. Bauer, N. Maulide, Chem. Sci. 2021, 12, 853-864.

[7] a) P. Mizar, T. Wirth, Angew. Chem. Int. Ed. 2014, 53, 5993-5997; b) H. Jiang, H. Zhang, W. Xiong, C. Qi, W. Wu, L. Wang, R. Cheng, Org. Lett. 2019, 21, 1125-1129; c) A. A. More, G. K. Pathe, K. N. Parida, S. Maksymenko, Y. B. Lipisa, A. M. Szpilman, J. Org. Chem. 2018, 83, 2442-2447; d) B. Sundararaju, M. Achard, C. Bruneau, Chem. Soc. Rev. 2012, 41, 4467-4483; e) L. Jiang, Z. Wang, M. Armstrong, M. G. Suero, Angew. Chem. Int. Ed. 2021, 60, 6177-6184; f) E. A. Merritt, B. Olofsson, Synthesis 2011, 2011, 
517-538; g) G. C. Geary, E. G. Hope, K. Singh, A. M. Stuart, RSC Advances 2015, 5, 16501-16506; h) H. K. Minhas, W. Riley, A. M. Stuart, M. Urbonaite, Org. Biomol. Chem. 2018, 16, 7170-7173.

$\left.{ }^{8}\right] \quad$ M. Fujio, A. Moriyasu, T. Tatsuo, I. Juichi, Bull. Chem. Soc. Jpn. 1978, 51, 335-336.

$\left[{ }^{9}\right] \quad$ a) S. Arava, J. N. Kumar, S. Maksymenko, M. A. Iron, K. N. Parida, P. Fristrup, A. M. Szpilman, Angew. Chem. Int. Ed. 2017, 56, 2599-2603; b) S. Maksymenko, K. N. Parida, G. K. Pathe, A. A. More, Y. B. Lipisa, A. M. Szpilman, Org. Lett. 2017, 19, 6312-6315; c) J. Li, A. Bauer, G. Di Mauro, N. Maulide, Angew. Chem. Int. Ed. 2019, 58, 9816-9819; d) A. Bauer, G. Di Mauro, J. Li, N. Maulide, Angew. Chem. Int. Ed. 2020, 59, 18208-18212; e) B. S. Martins, D. Kaiser, A. Bauer, I. Tiefenbrunner, N. Maulide, Org. Lett. 2021, 23, 2094-2098.

$\left[{ }^{10}\right] \quad$ T. Okuyama, T. Takino, T. Sueda, M. Ochiai, J. Am. Chem. Soc. 1995, 117, 3360-3367.

$\left[{ }^{11}\right] \quad$ P.-O. Norrby, T. B. Petersen, M. Bielawski, B. Olofsson, Chem. Eur. J. 2010, 16, 8251-8254.

$\left.{ }^{12}\right] \quad$ a) M. Ochiai, Y. Takeuchi, T. Katayama, T. Sueda, K. Miyamoto, J. Am. Chem. Soc. 2005, 127, 12244-12245; b) T. Hokamp, T. Wirth, Chem. Eur. J. 2020, 26, 10417-10421

$\left.{ }^{[13}\right]$ a) T. Nabana, H. Togo, J. Org. Chem. 2002, 67, 4362-4365; b) K. C. Nicolaou, T. Montagnon, T. Ulven, P. S. Baran, Y. L. Zhong, F. Sarabia, J. Am. Chem. Soc. 2002, 124, 5718-5728; c) M. Yoshida, K. Fujikawa, S. Sato, S. Hara, ARKIVOC, 2003, 36-42; d) A. E. Allen, D. W. C. MacMillan, J. Am. Chem. Soc. 2010, 132, 4986-4987.

[14] G. M. Kiefl, T. Gulder, J. Am. Chem. Soc. 2020, 142, 20577-20582.

$\left.{ }^{[15}\right] \quad$ A. Sanz-Marco, S. Martinez-Erro, M. Pauze, E. Gómez-Bengoa, B. Martín-Matute, Nat. Commun. 2019, $10,5244$.

$\left[{ }^{16}\right] \quad$ A. K. Ghosh, M. Brindisi, J. Med. Chem. 2015, 58, 2895-2940.

[17] a) Y. Peng, J. Liu, C. Qi, G. Yuan, J. Li, H. Jiang, Chem. Commun. 2017, 53, 2665-2668; b) E. Speckmeier, M. Klimkait, K. Zeitler, J. Org. Chem. 2018, 83, 3738-3745; c) H. Jiang, H. Zhang, W. Xiong, C. Qi, W. Wu, L. Wang, R. Cheng, Org. Lett. 2019, 21, 11251129.

$\left.{ }^{18}\right] \quad$ B. M. Trost, J. Xu, M. Reichle, J. Am. Chem. Soc. 2007, 129, 282-283.

$\left.{ }^{19}\right] \quad$ X. Wang, A. Studer, Acc. Chem. Res. 2017, 50, 1712-1724.

${ }^{[20}$ C. R. Gonçalves, M. Lemmerer, C. J. Teskey, P. Adler, D. Kaiser, B. Maryasin, L. González, N. Maulide, J. Am. Chem. Soc. 2019, $141,18437-18443$.

$\left.{ }^{21}\right] \quad$ J. Blom, G. J. Reyes-Rodríguez, H. N. Tobiesen, J. N. Lamhauge, M. V. Iversen, C. L. Barløse, N. Hammer, M. Rusbjerg, K. A. Jørgensen, Angew. Chem. Int. Ed. 2019, 58, 17856-17862.

$\left.{ }^{22}\right] \quad$ C. Zhu, Y. Zhang, H. Zhao, S. Huang, M. Zhang, W. Su, Adv. Synth. Catal. 2015, 357, 331-338.

$\left.{ }^{[23}\right] \quad$ a) Y. G. Lee, K. Ishimaru, H. Iwasaki, K. Ohkata, K. Akiba, J. Org. Chem. 1991, 56, 2058-2066; b) Y. Nakamura, Y. Ozeki, K. Uneyama, J. Fluorine Chem. 2008, 129, 274-279.

$\left.{ }^{24}\right] \quad$ A. D. Becke, J. Chem. Phys. 1993, 98, 5648-5652.

[25] Y. Zhao, D. G. Truhlar, Theor. Chem. Acc. 2008, 120, 215-241.

$\left.{ }^{26}\right]$ Gaussian 16, Revision C.01, Frisch, M. J.; Trucks, G. W.; Schlegel, H. B.; Scuseria, G. E.; Robb, M. A.; Cheeseman, J. R.; Scalmani, G.; Barone, V.; Petersson, G. A.; Nakatsuji, H.; Li, X.; Caricato, M.; Marenich, A. V.; Bloino, J.; Janesko, B. G.; Gomperts, R.; Mennucci, B.; Hratchian, H. P.; Ortiz, J. V.; Izmaylov, A. F.; Sonnenberg, J. L.; Williams-Young, D.; Ding, F.; Lipparini, F.; Egidi, F.; Goings, J.; Peng, B.; Petrone, A.; Henderson, T.; Ranasinghe, D.; Zakrzewski, V. G.; Gao, J.; Rega, N.; Zheng, G.; Liang, W.; Hada, M.; Ehara, M.; Toyota, K.; Fukuda, R.; Hasegawa, J.; Ishida, M.; Nakajima, T.; Honda, Y.; Kitao, O.; Nakai, H.; Vreven, T.; Throssell, K.; Montgomery, J. A., Jr.; Peralta, J. E.; Ogliaro, F.; Bearpark, M. J.; Heyd, J. J.; Brothers, E. N.; Kudin, K. N.; Staroverov, V. N.; Keith, T. A.; Kobayashi, R.; Normand, J.; Raghavachari, K.; Rendell, A. P.; Burant, J. C.; lyengar, S. S.; Tomasi, J.; Cossi, M.; Millam, J. M.; Klene, M.; Adamo, C.; Cammi, R.; Ochterski, J. W.; Martin, R. L.; Morokuma, K.; Farkas, O.; Foresman, J. B.; Fox, D. J. Gaussian, Inc., Wallingford CT, 2016

$\left.{ }^{27}\right] \quad$ a) Catalano, L.; Cavallo, G.; Metrangolo, P.; Resnati, G. Halogen Bonding in Hypervalent lodine Compounds. In Hypervalent lodine Chemistry; Wirth, T., Ed.; Topics in Current Chemistry, Springer: Cham, Switzerland, 373, 289- 309 (2016). b) Y. Wang, P. Su, ACS Omega 2020, 5, 21862-21872. 